\title{
Leading in a Complex Healthcare Ecosystem
}

\author{
Janice Pittman \\ Union University \\ Matthew Kolakowski \\ Valdosta State University
}

Today's healthcare environment requires an examination of what it means to be a fully competent leader. As a result, an upsurge in interest in healthcare management competencies has resulted. The present study utilizes a diverse group of informants as health management practitioners, multi-disciplinary faculty groups, and health service consumers. Using the competency directory published by the Healthcare Leadership Alliance (HLA), this study examined which traits are essential in providing quality healthcare services. Using survey data collected from 139 respondents, this study reveals that leadership was the only statistically significant competency.

Keywords: healthcare management, health professionals, competencies, leadership

\section{INTRODUCTION}

The complexity of healthcare systems across the U.S. has gradually risen since the 2010 passage of the Affordable Care Act (ACA). Before 2010, Drucker (2012) observed that "the largest healthcare institutions in human history might be the most complex, and that even small healthcare organizations are barely manageable"(Drucker, 2012). Several years have passed after these observations; however, the pressures put on leaders by this degree of difficulty and healthcare management educators have not diminished. Also, health care administrators navigate a systemically dynamic network of a socially and politically driven environment. Declining reimbursements, increased cost of indigent care, increasing shortages of skilled health care practitioners, and inadequate implementation of performance and safety indicators (Stefl, 2008). In a world in which demand for health services is increasingly growing, it is only appropriate to determine current and future leaders' competence in health care.

Don Seymour commented on the state of healthcare between 1998 and 2008 by writing, " taking care of more people who have growing expectations and more complex medical needs while providing increasingly sophisticated care with relatively fewer resources is becoming the new norm " (Stefl, 2008). If the new standard is uncertainty, cost shortages, and increased patient volume, have healthcare and educational programs kept pace? Several studies (Calhoun et al., 2002; Bradley, 2003; Kovner, 2001; Kovner and Rundall, 2006; Ross et. al., 2002; Westera, 2001) have measured and built leadership competencies in healthcare; however, implementation across the continuum of care has been erratic and inconsistent. Since several studies have discussed competency building models, the question now becomes: 
Have we incorporated all appropriate stakeholder feedback in creating leadership competencies in the health service?

\section{Purpose of the Study}

This study aims to evaluate leadership competencies in healthcare from the perspective of scholars, health officials, and customers and consumers (payers and patients) of healthcare services. The framework employed tests multiple stakeholders' views on which skill sets are crucial in delivering high-quality patient care. Three primary informant groups, health care professionals, multi-disciplinary faculty groups, and health service users, replied to these critical issue areas in terms of the competencies expected by those entering and practicing in the field.

Competencies assess the capacity of health care managers to:

1. Effect an integral part of one's success at work.

2. Optimize healthcare service quality.

3. Be assessed against agreed criteria and strengthened by continuous training and growth (Love and Ayadi, 2016).

\section{The Competency Movement}

The evidentiary approach to education and leadership in health care management did not arise overnight (Kovner and Rundall, 2006). Although evidentiary-based medicine has been in use for decades, this principle faced substantial delays in adopting both leadership in health care management and educational circles. From curriculum design in education to organizational leadership development, health care remains one of the most challenging environments for developing effective, evidence-based leadership practices. Healthcare administration has made strides in the practice of evidentiary leadership, although organizational complexity is still growing. The age-standardized mortality rate per 100,000 population (95 percent UI) resulting from the adverse effects of medical treatment (AEMT) will use to assess this progression. The age-standardized mortality rate resulting from AEMT declined from 1.46 to 1.15 per 100,000 of the United States population from 1990 to 2016 (Sunshine et al., 2019). This 21.4 percent decline in AEMT-related deaths indicates that the development of healthcare administration competencies is positive but has not yet achieved its maximum potential in the profession.

HLA is a group of professional organizations that have been at the forefront of establishing competencies in healthcare administration based on facts. These collaborations include:

- American College of Healthcare Executives (ACHE)

- American College of Physician Executives (ACPE)

- American Organization of Nurse Executives (AONE)

- Healthcare Financial Management Association (HFMA)

- Healthcare Information and Management Systems Society (HIMSS)

- Medical Group Management Association (MGMA)

These groups represent more than 100,000 practitioners in the healthcare sector and, through a shared interest in developing leadership skills in healthcare, formed a task force for competencies. Subsequently, this task force established a directory of 300 statements of competence, which influenced how four associations (ACHE, HFMA, HIMSS, and ACMPE) decided knowledge, skills, and abilities (KSAs) for certification examinations. Renowned psychometric firms ensured their (ACHE, HFMA, HIMSS, and ACMPE) processes were accurate and valid. In general, the HLA certification process allows for the demonstration of expertise to early healthcare administration professionals. Via the qualification process for HLA organizations, healthcare managers should be able to demonstrate expertise in these five areas of competence:

1. Communication and Relationship Management: Ability to communicate with internal and external customers simply and concisely and create and maintain ties.

2. Leadership: the ability to encourage individual and organizational achievement, build and accomplish a shared vision, and navigate change with success. 
3. Professionalism: Willingness to reconcile personal and organizational behavior with ethical and professional practices that involve patient and community accountability.

4. Healthcare climate knowledge: Illustrated understanding of the healthcare system and the environment in which healthcare administrators and providers work.

5. Business skills and knowledge: applying business concepts to the healthcare environment, including system thinking.

These expertise function as clusters that transcend organizational settings and are relevant in the operating environment (Ross et al., 2002). Since 1990, these competence domains' capacity to transcend individual and organizational settings has likely been a contributing factor in AEMT's 21.4 percent reduction. Promising is the potential that this body of information has shown to break down barriers between health management practitioners and provide a stronger foundation for collaboration (Stefl, 2008). Given that leadership is central to healthcare managers' success, the leadership domain anchors the HLA model (Stefl, 2008). All other domains originate from the leadership area but also feed and educate leadership from the other competencies. The two-way arrows outside the circles in Figure 1 show that the other four domains borrow from one another and share overlapping KSAs.

\section{FIGURE 1}

\section{HEALTHCARE LEADERSHIP ALLIANCE COMPETENCY MODEL}

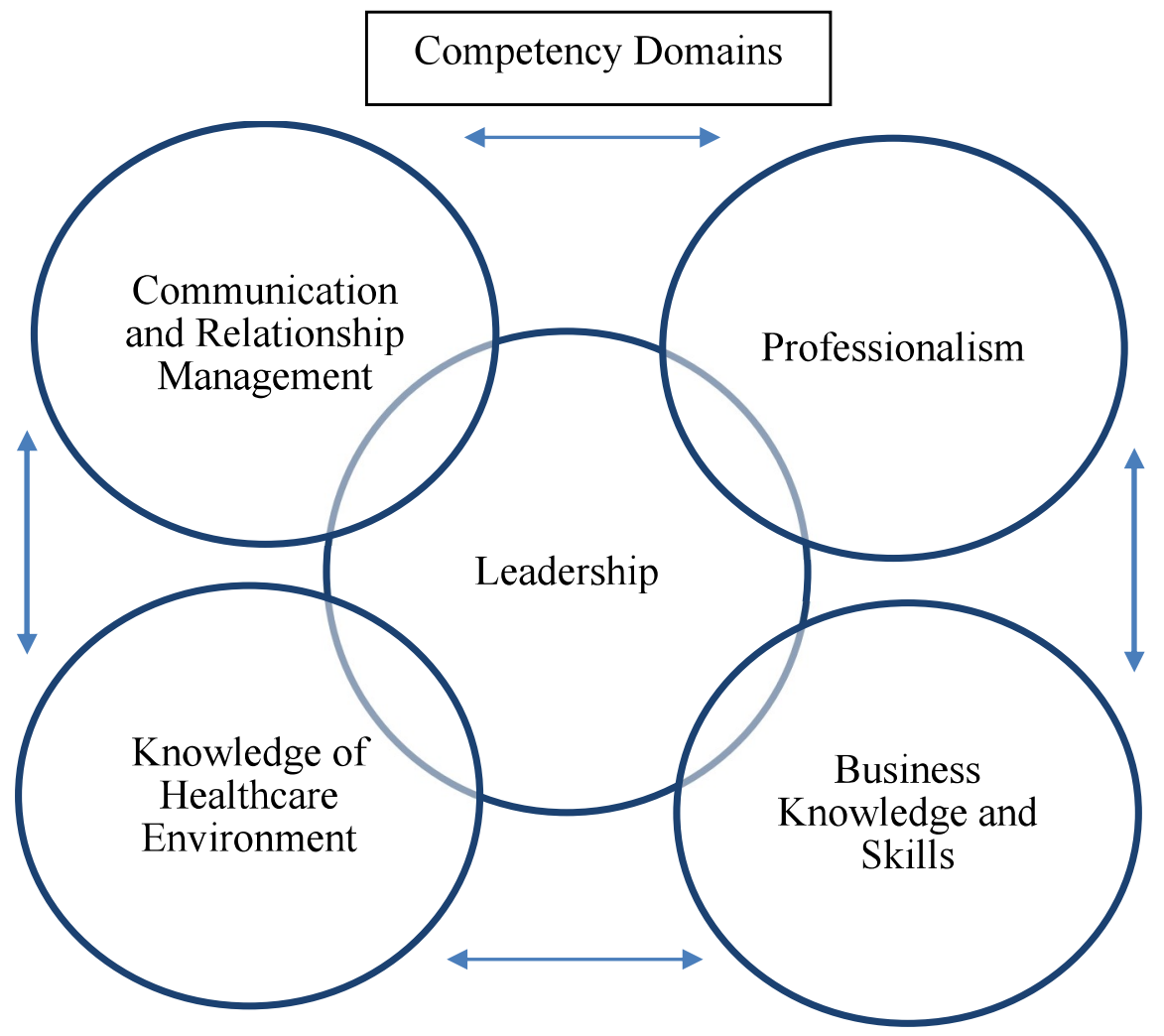

Source: 2005(C), All Rights Reserved by Members of the HLA Competency Task Force: American College of Healthcare Executives, American College of Physician Executives, American Organization of Nurse Executives, Healthcare Financial Management Association, Healthcare Information and Management Systems Society, and the certification body of the Medical Group Management Association-American College of Medical Practice Executives. 


\section{Shared Framework for Competency Development}

One of the disadvantages of skill growth relies on various interests (Shewchuk et al., 2006). Key domains of competence are first developed; then, examples derive from how one may demonstrate mastery (Shewchuk et al., 2006). This can lead to a loss of meaning in critical results as domains are separated from contexts and real behaviors. With these various obstacles and no possible direction for a "one size fit all" solution, a baseline of core competencies is important to gauge. Although competency development has included healthcare management services, and many professional associations, the customer (patient) has not been included. Subsequently, the inclusion of diverse perspectives on skills growth is important.

ACA has catalyzed a drive towards integrated structures such as Accountable Care Organization (ACOs), Physician-Hospital Organizations (PHOs), and Independent Physician Associations (IPAs). This trend has challenged healthcare executives to possess diverse skill sets, including health system management, physician leadership, risk management, and quality management. The sheer complexity of competencies in healthcare indicates that "there is no other sector where knowing core competencies is as important as it is today" (Ross et al. 2002). This research uses a twenty-two question self-report short survey by the American College of Healthcare Executives (ACHE) to assess the five competency domains mentioned in Figure 1. Four items from the American Health Values Survey incorporate the demographic information needed. Based on that interpretation, the following two hypotheses are proposed:

H1: Respondents, regardless of education level, will opt for healthcare administrators with diverse and well-rounded competency sets.

H2: Level of education will positively influence the degree respondents desire to access high-quality healthcare administrators and services.

\section{METHODS}

\section{Participants and Procedures}

This study attempts to gain a community perspective on what healthcare administration competency domains are perceived to be linked to high-quality healthcare services. We have drawn from literature (Bradley, 2003; Calhoun et al., 2002; Kovner, 2001; Ross et al., 2002; Westera, 2001) to develop an abbreviated yet impactful measurement of healthcare administrator competency domains. The instrument was constructed in Qualtrics to ensure quality control, data security, and distribution's uniformity to all potential respondents.

Using Qualtrics, we reached out to 1,000 potential respondents that include healthcare administrators, faculty, and staff members from Valdosta State University and received 139 usable responses for a response rate of $13.9 \%$. The Qualtrics survey included four demographic questions: 1. The respondent's occupation, 2. Level of education, 3. Gender and 4. Importance of access to high-quality health care in the community in which they currently reside. Twenty-two questions from the 2018 American College of Healthcare Executives (ACHE) competencies assessment tool measured the respondent's penchant for each of the five competency domains. The five competency domains measured include Communication and Relationship Management, Professionalism, Leadership, Knowledge of the Healthcare Environment, and Business Knowledge and Skills.

\section{Measures}

Communication and Relationship Management. Communication and relationship management skills were measured with 3 -items on a five-point Likert scale ( $1=$ Not Important, $5=$ Very Important $)$ to indicate their perception of this healthcare administration competency domain.

Leadership. Leadership was measured with 3 -items on a five-point Likert scale $(1=$ Not Important, $5=$ Very Important) to indicate their perception of this healthcare administration competency domain. Leadership in this study was defined as the ability to inspire individual and organizational excellence, create a shared vision, and successfully manage change. 
Professionalism. Professionalism was measured with 3-items on a five-point Likert scale (1= Not Important, $5=$ Very Important) to indicate their perception of this healthcare administration competency domain. Professionalism in this study was defined as the alignment of personal and professional organizational conduct with ethical and professional standards that include a patient and community's responsibility.

Knowledge of the Healthcare Environment. Knowledge of the healthcare environment was measured with 7-items on a five-point Likert scale ( $1=$ Not Important, $5=$ Very Important) to indicate their perception of this healthcare administration competency domain. Knowledge of the healthcare environment in this study was defined as the understanding of the healthcare system and environment in which healthcare managers and providers function and how patients receive care.

Business Skills and Knowledge. Business skills and knowledge was measured with 6-items on a fivepoint Likert scale ( $1=$ Not Important, $5=$ Very Important) to indicate their perception of this healthcare administration competency domain. Business skills and knowledge in this study were defined as applying business principles, including systems thinking, to the healthcare environment.

\section{Dependent Variable}

Importance of Access to High-Quality Healthcare. The dependent variable selected was access to highquality healthcare. This allowed for analysis of healthcare administration competencies and how the respondent's penchant for access to high-quality healthcare services impacts each domain.

\section{Measure Validation}

Since no previous scholarly studies were located after searching four major databases (ProQuest, JSTOR, Scopus, and EBSCO, it was necessary to establish item reliability, composite reliability (CR), convergent, and discriminant validity for each construct. We examined each construct based on standardized items. After establishing acceptable reliability for each construct, we conducted a confirmatory factor analysis (CFA) to test potential theoretical linkage. The CFA will be used to confirm convergent and discriminant validity and ensure the homogeneity of domain items.

The communication and relationship management construct was created with three questions from the 2018 ACHE competency assessment tool. For the communications and relationship management construct, Cronbach's Alpha based upon standardized items was .72, which exceeded the 70 cut off proposed (Cronbach, 1951). The leadership construct was created with three questions from the ACHE instrument. For the leadership construct, Cronbach's Alpha based upon the standardized items was .74, which exceeded the .70 cutoff proposed by Cronbach. The professionalism construct was created with two questions from the ACHE instrument, which measured the ability to align personal and organizational conduct. For the professionalism construct, Cronbach's Alpha based on the standardized items was .72, which exceeded the .70 cutoff proposed by Cronbach. The business skills and knowledge construct were created with four questions from the ACHE instrument, which measured the ability to apply business principles, including systems thinking, to the healthcare environment. For the business skills and knowledge construct, Cronbach's Alpha based on standardized items was .85, which exceeded the 70 cutoff proposed by Cronbach. The knowledge of the healthcare environment construct was created with six questions from the ACHE instrument, which measured the understanding of the healthcare system and environment in which healthcare managers and providers function. For the knowledge of the healthcare environment construct, the Cronbach's Alpha based on standardized items was .64, which did not meet Cronbach's proposed .70 cut off and was subsequently dropped from further analysis.

Before factor analysis, the factorability of the data was assessed. Applying Hair et al. (2006) sampling adequacy cutoff criteria of .50, five additional items were dropped, including the professionalism construct (Hair et al., 1998). The model retained includes 11 items across three competency domains- communication and relationship management, leadership, and business skills and knowledge. Table 1 summarizes the composite reliability and convergent validity of each construct (Hu and Bentler, 1999). 


\section{TABLE 1 \\ SUMMARY OF FACTOR COMPOSITE RELIABILITY (CR) AND AVERAGE VARIANCE EXTRACTED (AVE) (N=139)}

\begin{tabular}{lcc}
\hline Construct & $C R$ & $A V E$ \\
\hline Leadership & 0.74 & 0.68 \\
Communication and Relationship Management & 0.72 & 0.53 \\
Business Skills and Knowledge & 0.84 & 0.68 \\
\hline
\end{tabular}

Note: CR suggested minimum is .70 and AVE suggested minimum is .50

Each construct's composite reliabilities showed reasonable internal consistency as each measure was over the 70 cutoff criteria (Kline, 2003). To check discriminant validity, this study used the guidelines proposed (Kline, 2003). Table 2 summarizes the results, which indicate that "the measured variables have more in common with the construct they are associated with than they do with the other constructs" (Kline, 2003).

TABLE 2

FACTOR INTER-ITEM CORRELATIONS (N=139)

\begin{tabular}{lccc}
\hline Construct & Leadership & $\begin{array}{c}\text { Communication } \\
\text { and Relationship } \\
\text { Management }\end{array}$ & $\begin{array}{c}\text { Business Skills } \\
\text { and Knowledge }\end{array}$ \\
\hline Leadership & 1.000 & .491 & .624 \\
Communication and Relationship Management & .491 & 1.000 & .383 \\
Business Skills and Knowledge & .624 & .383 & 1.000 \\
\hline
\end{tabular}

Note: factor inter-item correlation calculated utilizing JASP

The resulting convergent and discriminant validity reasonably confirm that the indicators and constructs warrant investigating the overall model fit. Following the guidelines set forth by Kenny (2015), the fit indices assessed in this study include the following: Chi-Square of Model Fit, Root Mean Square Error of Approximation (RMSEA), Comparative Fit Index (CFI), Tucker Lewis Index (TLI), and Standardized Root Mean Square Residual (SRMR) (Kenny, 2015). Each of these statistical fit indices is widely utilized and provides a reasonable set of criteria to assess the fit of a model. The chi-square of the proposed model was statistically significant $(\mathrm{P}=0.01)$; however, this statistic requires further examination. The present model had 38 degrees of freedom and a value of 59.115 for a ratio of 1.55 (Hu and Bentler, 1999). The chi-square statistic's ratio to the degrees of freedom provides the first goodness of fit metric in which ratios less than or equal to 2 indicated a good fit (Wheaton et al., 1997).

The next measure examined was RMSEA, and was assessed using the following criteria: $0.01,0.05$, and 0.08 indicated excellent, good, and mediocre fit, respectively (Hu and Bentler, 1999). The RMSEA of the proposed study was 0.063 , which indicates a reasonable fit ( $\mathrm{Hu}$ and Bentler, 1999). The next two fit indices examined were the CFI and the TLI. As defined by Hu and Bentler (1999), the acceptable fit is $>.90$ for both indices. In this study, the CFI was 0.96 , and the TLI was 0.94 , which indicates a good fit (Hu and Bentler, 1999). The final index examined was the SRMR in which the acceptable fit $\mathrm{P}<0.08$. In this study, the SRMR was 0.06, which indicates a good fit because it is less than 0.08 (Hu \& Bentler, 1999). To summarize, the examination of each fit index in Table 3 shows that the overall model demonstrates a reasonable fit compared to the acceptable levels. 
TABLE 3

SUMMARY OF CONFIRMATORY FACTOR ANALYSIS FIT INDICES (N=139)

\begin{tabular}{lcc}
\hline Fit Index & Actual Results & Acceptable Fit \\
\hline Chi-Square & 0.01 & $<0.05$ \\
RMSEA & 0.06 & $<0.08$ \\
SRMR & 0.06 & $<0.08$ \\
TLI & 0.94 & $>0.90$ \\
CFI & 0.96 & $>0.90$
\end{tabular}

Note: Fit Indices were calculated utilizing JASP.

The item reliability, $\mathrm{CR}$, and convergent and discriminant validity of the resulting model provides the opportunity to explore the effects of the remaining competency domains and the impact of the level of education.

\section{RESULTS}

Before proceeding with regression analysis, the indicators of communication and relationship management, leadership, and business skills and knowledge were combined and mean centered according to the guidelines set forth by Aguinis (2004) (Aguinis, 1995). This process ensured that each construct's mean was set to 1.000, and it decreased the correlation between the multiplicative terms (Aguinis, 1995). For Hypothesis 1, communication and relationship management, leadership, and business skills and knowledge will be isolated as the independent variables and the importance of access to high-quality healthcare services as the dependent variable. For Hypothesis 2, communication and relationship management, leadership, and business skills and knowledge will be isolated as the independent variable and the importance of access to high-quality healthcare services as the dependent variable. The education level will be a selection variable and separate various groups of respondents by education to discern potential variation. Table 4 below summarizes each of the three models tested- All respondents, respondents with at least a bachelor's degree $(\mathrm{N}=73)$, and respondents that graduate high school or technical college $(\mathrm{N}=66)$.

From the three regression models, no conclusive evidence supported hypothesis 1 that generalizable healthcare administration competencies are preferred over specialized leaders. For hypothesis 2, support was found that education level impacts how respondents perceive the importance of healthcare administrator competency domains. It appears that as the level of education rises, so does the importance of having competent healthcare administrators providing health services.

\section{TABLE 4}

SUMMARY OF REGRESSION ANALYSIS FOR HEALTHCARE COMPETENCY DOMAIN (N=139)

\begin{tabular}{|c|c|c|c|c|c|c|c|c|c|}
\hline \multirow[b]{2}{*}{ Variable } & \multicolumn{3}{|c|}{$\begin{array}{l}\text { Model } 1 \\
\text { (All Respondents) }\end{array}$} & \multicolumn{3}{|c|}{$\begin{array}{c}\text { Model } 2 \text { (Respondents with } \\
\text { Bachelor's Degree or } \\
\text { Higher, N=73) }\end{array}$} & \multicolumn{3}{|c|}{$\begin{array}{c}\text { Model } 3 \text { (Respondents with } \\
\text { Trade/Technical School or } \\
\text { High School Graduate, } \\
\text { N=66) }\end{array}$} \\
\hline & $\bar{B}$ & $S E B$ & $P$-Value & $B$ & $S E B$ & P-Value & $B$ & $S E B$ & P-Value \\
\hline $\begin{array}{l}\text { Communication } \\
\text { and } \\
\text { Relationship } \\
\text { Management }\end{array}$ & 0.077 & 0.062 & .21 & 0.195 & 0.055 & $.001^{* *}$ & -0.110 & 0.131 & .40 \\
\hline Leadership & 0.092 & 0.046 & $.04 *$ & 0.103 & 0.037 & $.007 * *$ & 0.108 & 0.110 & .32 \\
\hline
\end{tabular}




\begin{tabular}{|c|c|c|c|c|c|c|c|c|c|}
\hline $\begin{array}{l}\text { Business Skills } \\
\text { and Knowledge }\end{array}$ & -0.257 & 0.047 & .55 & -0.076 & 0.040 & .06 & 0.053 & 0.100 & .59 \\
\hline$R^{2}$ & & 0.045 & & & 0.241 & & & -0.018 & \\
\hline$F$ & & 3.158 & & & 8.608 & & & 0.621 & \\
\hline
\end{tabular}

\section{DISCUSSION AND IMPLICATIONS}

Ironically, in this study, the only statistically relevant competency area was leadership across multiple models. In several previous surveys, the top-ranked skills (Bradley, 2003; Calhoun et al., 2002; Kovner, 2001; Love and Ayadi, 2016; Ross et al., 2002; Westera, 2001) were leadership to include leading health care professionals and promote the strategic course. As the industry continues to expand in size and complexity, leadership will be the key tool for managing healthcare administrators' competence. This transition has already changed how doctors practice medicine, and benefits are offered to ancillary service providers. Also, hospitals are shifting the way they view patient care and are switching from focusing on patient volume to quality of treatment.

Healthcare management will now have to direct, coordinate, and maintain the quality vision for care rendered when major insurers have tied financial compensation programs to that criterion. Collaboration with Chief Medical Officers (CMOs) would need to become more complex as physician incentives have changed to keep patients out of the hospital, minimize readmissions, and the number of days the patients are in the hospital. The time-honored adage that no margin, no goal is more important than ever in healthcare operations. Hospitals across the United States will be rewarded with the introduction of payment schemes focused on population control and efficiency, which will ultimately require a new generation of health care managers to be more astute with resource distribution across the organization.

This newfound sharing of risk would also entail investment in infrastructure, workflow, and care management systems. The leadership domain does not mean that managers in health care should become masters of several hundred skill sets; instead, it suggests that transformational leadership will become a priority in effective health systems. It is also clear that healthcare managers' competency domains will continue to change and move as the age of healthcare reform and transformation is upon us.

\section{LIMITATIONS}

As with all empirical studies, there are drawbacks to this research. This research uses self-reported, cross-sectional data from a diverse community of respondents; thus, it is not possible to infer causality. Also, the response rate of 13.9 percent for individual and organizational email surveys is at the low end of averages (Baruch, and Holtom, 2008). More detailed follow-up approaches (or method) will be needed in future iterations for engaging the potential pool of respondents. As response rates had fallen from 64.4 percent in 1975 to 48.3 percent in 2005, a diverse interaction strategy (or method) is likely required to achieve full participation. Another constraint is the sample linked. This analysis's data were obtained using a single collection method from a sole source (Qualtrics). Isolating particular groups and adding more items that assess communication and relationship management, leadership, and business skills could be desirable to avoid possible bias in the recall.

The determination of average years of healthcare experience will help analyze whether the healthcare managers and stakeholders being surveyed are considered novices or experts in the field. Future research may include questions regarding medicine areas to gauge which health system sectors prefer those competency domains over another. Finally, additional studies may concentrate on constructs for the calculation. Although many professional associations have made time-consuming attempts to quantify competency domains in the administration of healthcare, there are few instances where analytical assessment methods were used. It is likely that respondents faced uncertainty due to the questions' ambiguity and may benefit from further clarification and empirical research. Also, the similarity of the 
questions between knowledge of the healthcare environment and business skills knowledge contributed to a decrease in one build before testing the hypothesized model.

\section{CONCLUSION}

The creation, growth, and improvement of healthcare competency domains drive the operational environment's transformation for health services. Healthcare managers have to manage a vast array of threats effectively when managing a world that increasingly grows in complexity. One of the aims of this study was to show that a diverse community of stakeholder feedback is needed to establish healthcare administrator competencies. The creation and comprehension of healthcare managers' competency domains cannot be static or a one-time occurrence from the analyzes presented. As the healthcare environment continues to change at a rapid pace, leadership in health systems will continue to be diverse and remain a priority and improve the calculation in which domains carry effect.

\section{REFERENCES}

Aguinis, H. (1995). Statistical power problems with moderated multiple regression in management research. Journal of Management, 21(6), 1141-1158.

Aguinis, H. (2004). Regression Analysis for Categorical Moderators. Guilford Press.

American Hospital Association., \& American College of Healthcare Executives. (2008). Futurescan: Healthcare trends and implications, 2008-2013. Chicago, IL: Health Administration Press.

Bradley, E.H. (2003). Use of evidence in implementing competency-based healthcare management teaching. The Journal of Health Administration Education, 20(4), 287-304.

Baruch, Y., \& Holtom, B.C. (2008). Survey response rate levels and trends in organizational research. Human Relations, 61(8), 1139-1160.

Calhoun, J.G., Davidson, P.L., Sinioris, M.E., Vincent, E.T., \& Griffith, J.R. (2002). Toward an understanding of competency identification and assessment in health care management. Quality Management in Healthcare, 11(1), 14-38.

Calhoun, J.G., Vincent, E.T., Baker, G.R., Butler, P.W., Sinioris, M.E., \& Chen, S.L. (2004). Competency identification and modeling in healthcare leadership. The Journal of Health Administration Education, 21(4), 419-440.

Cronbach, L.J. (1951). Coefficient alpha and the internal structure of tests. Psychometrika, 16(3), 297334.

Drucker, P. (2012). Managing in the Next Society. Routledge.

Flavell, J.H. (1979). Metacognition and cognitive monitoring: A new area of cognitive-developmental inquiry. American Psychologist, 34(10), 906.

Hair, J.F., Black, W.C., Babin, B.J., Anderson, R.E., \& Tatham, R.L. (1998). Multivariate data analysis (Vol. 5, No. 3, pp. 207-219). Upper Saddle River, NJ: Prentice Hall.

Hu, L.T., \& Bentler, P.M. (1999). Cutoff criteria for fit indexes in covariance structure analysis: Conventional criteria versus new alternatives. Structural Equation Modeling: A MultiDisciplinary Journal, 6(1), 1-55.

Jaccard, J., Turrisi, R., \& Jaccard, J. (2003). Interaction effects in multiple regression (No. 72). Sage. Kaplowitz, M.D., Lupi, F., Couper, M.P., \& Thorp, L. (2012). The effect of invitation design on web survey response rates. Social Science Computer Review, 30(3), 339-349.

Kenny, D.A. (2015). Measuring Model Fit.

Kline, P. (2013). Personality: The psychometric view. Routledge.

Kovner, A.R. (2001). The future of health care management education: an evidence-based approach. The Journal of Health Administration Education, 107.

Kovner, A.R., \& Rundall, T.G. (2006). Evidence-based management reconsidered. Frontiers of Health Services Management, 22(3), 3. 
Love, D.B., \& Ayadi, M.F. (2016). Redefining the core competencies of future healthcare executives under healthcare reform. Administrative Issues Journal: Connecting Education, Practice, and Research, 5(2).

Ross, A., Wenzel, F.J., \& Mitlyng, J.W. (2002). Leadership for the future: Core competencies in healthcare. Health Administration Press.

Shewchuk, R.M., O'Connor, S.J., Fine, D.J., \& Tyler, J.L. (2005). Building an understanding of the competencies needed for health administration practice. Journal of Healthcare Management, 50(1), 32.

Shewchuk, R.M., O Connor, S.J., \& Fine, D.J. (2006). Bridging the gap: Academic and practitioner perspectives to identify early-career competencies needed in healthcare management. Journal of Health Administration Education, 23(4), 366.

Stefl, M.E. (2008). Common competencies for all healthcare managers: the healthcare leadership alliance model. Journal of Healthcare Management, 53(6).

Sunshine, J.E., Meo, N., Kassebaum, N.J., Collison, M.L., Mokdad, A.H., \& Naghavi, M. (2019). Association of adverse effects of medical treatment with mortality in the United States: A secondary analysis of the global burden of diseases, injuries, and risk factors study. JAMA Network Open, 2(1), e187041-e187041.

Westera, W. (2001). Competences in education: A confusion of tongues. Journal of Curriculum Studies, 33(1), 75-88.

Wheaton, B., Muthen, B., Alwin, D.F., \& Summers, G.F. (1977). Assessing reliability and stability in panel models. Sociological Methodology, 8, 84-136.

White, K.R., Clement, D.G., \& Nayar, P. (2006). Management Competency Evaluation: Alumni Perceptions. The Journal of Health Administration Education. 